\title{
ORIGINAL ARTICLE Hearing among male firefighters: A comparison with hearing data from screened and unscreened male population
}

\author{
Tae Sun Kang ${ }^{1}$, Oi Saeng Hong ${ }^{2}$, Kyoo Sang Kim ${ }^{3}$ and Chung Sik Yoon ${ }^{1}$
}

\begin{abstract}
We investigated whether hearing loss is associated with firefighting. We conducted cross-sectional study comparing hearing threshold levels (HTLs) of 912 male firefighters with two hearing databases obtained from an otologically normal male Korean population (KONP) and a non-industrial noise-exposed male Korean population (KNINEP), considering age and the main roles of firefighters. Firefighters' age-adjusted HTLs were significantly worse than those of KONP (prevalence ratio $(P R)=5.29, P<0.001)$ but not different from those of KNINEP $(P R=0.99, P=0.550)$. Rescuers $(P R=1.005, P<0.001)$ had worse hearing than the KNINEP after age adjustment. Comparison of firefighters' HTLs (50th and 90th percentiles) with those of KONP and KNINEP by age and frequency showed that firefighters' HTLs had significant increases (poorer hearing) across most age groups and frequencies compared with KONP. Compared with KNINEP, firefighters' HTLs were worse in the younger age groups ( $<45$ years) but not different in the older age groups ( $>45$ years). In conclusion, the hearing thresholds of younger firefighters and rescuers were worse than expected by normal aging alone. Future research should include longitudinal studies to consider variable risk factors, such as military service, smoking, and so on.
\end{abstract}

Journal of Exposure Science and Environmental Epidemiology (2015) 25, 106-112; doi:10.1038/jes.2014.72; published online 5 November 2014

Keywords: audiogram; firefighter; hearing loss; noise; exposure; threshold

\section{INTRODUCTION}

Firefighting is one of the most hearing-critical occupations. The hearing health of firefighters concerns much more than hearing conservation. ${ }^{1,2}$ Hearing is crucial in preventing injury in the firefighting environment, where smoke often minimizes visual cues, and high levels of background noise and stress-related distraction are present. ${ }^{1}$ Firefighters should have adequate hearing acuity to hear a victim scream for help, to hear the low-pressure alarm from a self-contained breathing apparatus indicating that the device is running out of air, to hear sounds associated with imminent collapse, and to hear noises associated with changes in a fire pattern. ${ }^{1}$

Noise is a part of the causal mechanism leading to hearing injury and can cause hearing loss.,4 Firefighters are exposed intermittently to high-intensity noise. However, firefighters tend to accept noise exposure as inevitable. In particular, during responding emergency call, firefighters' serious health risks are ignored..$^{5}$

Some previous research has suggested that firefighters' hearing threshold levels (HTLs) decline faster than expected during their careers compared with age-matched members of the general population. ${ }^{6-9}$ However, a recent US study using data from hearing-conservation programs (HCPs) in two fire departments suggested that firefighters were not at risk for occupational noiseinduced hearing loss. ${ }^{10}$

Korean fire departments do not have HCPs. No baseline audiograms are recorded, and hearing protection devices are not provided. Also, until recently, few studies have been conducted in Asia exploring hearing levels in firefighters.
Thus the aim of this study was to investigate whether hearing loss is associated with a firefighting career in Korea. A crosssectional study was conducted to compare hearing thresholds of firefighters with two age-matched population-based data sets (one from a group of otologically screened normal Korean males (KONP (Korean otologically normal population)) with no noise exposure and one from a group of unscreened Korean males who had not been exposed to occupational noise (KNINEP (Korean non-industrial noise exposed population)).

\section{METHODS}

Subjects and Source Data

The subjects of this study were a total of 912 male firefighters (100\%) who worked in 4 of the 23 local fire departments in Seoul, Korea. The four fire departments (Guro, Mapo, Gwanak, Gwangjin) were randomly selected by geographical region. Firefighters' age ranged from 24 years to 59 years (mean age $=44$ years). The study included male firefighters only because of the small numbers of females (5\%) in fire service. Since 2004, the annual audiometric testing for firefighters has been performed in three hospitals that were approved by the Korean Ministry of Employment and Labor. A standard pure-tone audiometric testing was conducted at frequencies at $0.5 \mathrm{kHz}, 1 \mathrm{kHz}, 2 \mathrm{kHz}, 3 \mathrm{kHz}, 4 \mathrm{kHz}$, and $6 \mathrm{kHz}$ for both ears. HTLs were reported in 5-dB increments and HTLs were obtained between $-10 \mathrm{~dB}$ and $90 \mathrm{~dB}$.

This study used 2010 audiometric data of the firefighters that were obtained from the participating fire departments. Audiometric data included HTLs measured at test frequencies from $0.5 \mathrm{kHz}$ to $6 \mathrm{kHz}$, along with the participant's age and duration of service. The service duration was coded by month of each main role such as a fire suppressor, rescuer medical paramedic, driver, and office job. Firefighters are divided into field personnel and office personnel. Fire suppressors, rescuers, paramedics, and

${ }^{1}$ Department of Environmental Health and Institute of Health and Environment, Graduate School of Public Health, Seoul National University, Seoul, Korea; ${ }^{2}$ School of Nursing, University of California San Francisco, CA, USA and ${ }^{3}$ Seoul Medical Center, Seoul, Korea. Correspondence: Dr. Chungsik Yoon, Department of Environmental Health and Institute of Health and Environment, Graduate School of Public Health, Seoul National University, Gwanak-ro 1, Gwanak-gu, Seoul 151-742, Korea.

Tel.: +82 2880 2734. Fax: +8227459104.

E-mail: csyoon@snu.ac.kr

Received 19 February 2014; accepted 28 August 2014; published online 5 November 2014 
drivers are categorized into the field personnel. The office personnel are responsible for enforcing laws or regulations related to fire prevention. In general, firefighters are assigned to one major job task at the beginning of their career but occasionally they get rotated to different job tasks.

\section{The Screened and Unscreened Population for Comparison}

Firefighters' hearing status was compared with two hearing database of general population in Korea: (1) KONP and (2) KNINEP. The KONP is hearing data obtained from otologically normal healthy adults with no noise exposure. The KONP was consisted of a total of 2492 adults (male $=1250$ female $=1242$ ) with approximately 60 subjects (male 30, female 30 ) at each year of age from 20 to 59 years old. ${ }^{11}$ About $80 \%$ of the KONP participants were from Seoul area, the capital city of South Korea. KONP hearing data consisted of HTLs of both ears at frequencies of $0.5 \mathrm{kHz}, 1 \mathrm{kHz}, 2 \mathrm{kHz}, 3 \mathrm{kHz}$, $4 \mathrm{kHz}, 6 \mathrm{kHz}$, and $8 \mathrm{kHz}$. The standard pure-tone audiometric testing was performed in eight hospitals that were approved by the Korean Ministry of Employment and Labor. The tests were conducted with the calibrated audiometers at 2-dB steps either in the sound-treated fixed booth or in the portable booth, which was positioned in a site where the American National Standards Institute (ANSI) standard for background noise was met. ${ }^{12}$ HTLs were obtained between $-10 \mathrm{~dB}$ and $90 \mathrm{~dB}$. The HTLs at frequencies $(0.5 \mathrm{kHz}, 1 \mathrm{kHz}, 2 \mathrm{kHz}, 3 \mathrm{kHz}, 4 \mathrm{kHz}$, and $6 \mathrm{kHz})$ of 1130 males, aged from 24 to 59 years out of the entire KONP HTL DB were selected for comparison. To calculate PTA1234, average hearing threshold value at $1 \mathrm{kHz}, 2 \mathrm{kHz}, 3 \mathrm{kHz}$ and $4 \mathrm{kHz}$, only 677 subjects' data out of $1130 \mathrm{KNOP}$ males were used because 453 subjects were not measured at $3 \mathrm{kHz}$. Second comparison data are taken from the fifth KNHANES (Korean National Health and Nutrition Examination Survey) that was collected in 2011. KNHANES data included survey data on health and nutritional status among the general population in Korean. The subjects of KNHANES were chosen through a stratified multistage probability sampling procedure to serve as a nationally representative sample. The data included audiometric hearing tests and interviews of 6302 subjects aged $>12$ years. Audiometric tests were performed at a double-walled, sound-proof mobile audiometry booth (SAD-800; SONTEK, Korea) using a microprocessor puretone audiometry (SA-203, Entomed, Sweden) by well-trained examiners in both ears at frequencies of $0.5 \mathrm{kHz}, 1 \mathrm{kHz}, 2 \mathrm{kHz}, 3 \mathrm{kHz}, 4 \mathrm{kHz}$, and $6 \mathrm{kHz}$ in $5-\mathrm{dB}$ increments. HTLs were obtained between $-10 \mathrm{~dB}$ and $90 \mathrm{~dB}$. For the purpose of comparison, we selected hearing data of 1231 males (mean age $=43$ years, range from 24 to 59 years) who answered 'no' to the question: 'Have you ever been exposed to loud noise emitted from machine or generator for at least 3 months in workplace? Loud noise means noise was so loud that you had to speak in a raised voice to be heard'. We named this unscreened general population KNINEP, because subjects were not screened for any non-occupational noise exposure or otological diseases. ${ }^{13}$

Prevalence Ratio (PR) of Hearing Loss in Firefighters versus General Populations

There are several definitions of hearing impairment. In the occupational setting, hearing impairment is generally defined as a pure-tone average (PTA) of the HTLs for both ears that exceeds $25 \mathrm{~dB}$ at $1000 \mathrm{~Hz}, 2000 \mathrm{~Hz}$ $3000 \mathrm{~Hz}$, and $4000 \mathrm{~Hz}$ (PTA1234). ${ }^{14}$ We used it as a definition of hearing loss for comparison. The number of subjects from three groups exceeding these criteria for the average of the both ears was calculated. Hearing loss was calculated by main roles of the firefighter and five age groups. PR of hearing loss among firefighter and each general population was calculated by Cochran-Mantel-Haenszel method, stratified by five age groups.

An association with hearing loss and main role (duration in months) was examined by the generalized linear model (log link, Poisson distribution) with controlling age as a continuous variable. The PRs were calculated for firefighters, using each general population as the reference group. All reported $P$-values were two tailed, and $P<0.05$ was established as the level of significance.

\section{Comparison of Firefighters' HTLs with those of Screened and Unscreened Population}

Medians and selected other percentiles are commonly used to describe audiometric threshold distributions, because HTL distributions of population-based samples are usually positively skewed. ${ }^{15}$ For each test frequency and age group, medians and 90th percentiles of HTLs for Korean firefighters were compared with those from the two comparison groups. For the purpose of comparison, five age groups were used: 24-30, 31-40, $41-45,46-50$, and $>51$ years. The table for comparison of three groups' threshold levels consist of 60 cells, and each cell has median or 90th percentile threshold level of each frequency and age group. For each comparison cell, the HTLs of firefighters were judged as "better than," "not different from," or "worse than" KONP or KNINEP. To clarify the comparison, the medians with 95th percentile upper and lower confidence intervals for firefighters' HTLs were represented with those of KONP and KNINEP by audiogram.

There were no personal identifiers recorded in the database. The study protocol was approved by the institutional review board (IRB) of the Graduate School of Public Health in Seoul National University, South Korea.

\section{RESULTS}

PR of Hearing Loss in Firefighters versus General Populations Table 1 shows the prevalence and PR of hearing loss (PTA1234 $\geq 25 \mathrm{~dB}$ ) among firefighters and general populations. The average age of the 912 firefighters was $44 \pm 8$ years, which was not different from those of the comparison groups ( $44 \pm 11$ years in KONP, $43 \pm 10$ years in KNINEP). The HTLs of $1 \mathrm{kHz}, 2 \mathrm{kHz}$, $3 \mathrm{kHz}$, and $4 \mathrm{kHz}$ were averaged for the left and right ears of each subject (PTA1234). About 16.3\% of firefighters had hearing loss, compared with $3.4 \%$ of KONP and $17.6 \%$ of KNINEP. The PR for firefighters versus KONP was $5.29(3.34-8.39 ; P<0.001)$ and that for firefighters versus KNINEP was $0.99(0.95-1.03 ; P=0.550)$.

In terms of the major roles of firefighters, hearing loss was most prevalent in rescuers $(25.8 \%)$, followed by office workers $(16.6 \%)$, suppressors (16.4\%), paramedics (13.9\%), and drivers (13.8\%). The Cochran-Mantel-Haenszel test among the main roles of the firefighters, adjusting for age, demonstrated significant differences among the roles $(P=0.030)$.

Table 2 shows the PRs of hearing loss in firefighters compared with KONP, which is the result of generalized linear model (log

Table 1. Prevalence and prevalence ratio of hearing loss $\mathrm{s}^{\mathrm{a}}$ among firefighter and control groups.

\begin{tabular}{|c|c|c|c|c|c|c|c|c|}
\hline & Rescuer & Paramedic & Driver & Suppressor & Office worker & Subtotal & $K O N P$ & KNINEP \\
\hline${ }^{\mathrm{b}} \mathrm{PR}$ & \multicolumn{4}{|c|}{$\begin{array}{c}\text { Firefighters/KONP } \\
\text { Firefighters/KNINEP }\end{array}$} & \multicolumn{4}{|c|}{$\begin{array}{l}5.29(3.34 \sim 8.39, P<0.001) \\
0.99(0.95 \sim 1.03, P=0.550)\end{array}$} \\
\hline
\end{tabular}


link, Poisson distribution) for hearing loss in firefighters and KONP, combined with age and years of service for each main role of the firefighters. The service durations of all main roles were significant predictor of hearing loss, in particular, role as rescuer showed the highest risk $(P R=1.010, P<0.0001)$ than as any other main role. Although age was the strongest predictor as well, age effect became insignificant after service duration of main role had been entered into the regression equation ( $P R=1.022, P=0.0625)$.

The result of generalized linear model (log link, Poisson distribution) for hearing loss among firefighters and KNINEP is shown in Table 3. PRs for hearing loss increased with age $(\mathrm{RR}=1.077,95 \% \mathrm{Cl}: 1.063-1.091)$. Duration of service (months) in the role of a rescuer was the only significant predictor of hearing loss after adjusting for age ( $\mathrm{RR}=1.005,95 \% \mathrm{Cl}$ : 1.002-1.007).

\section{Percentile Distribution of HTLs}

The distributions of age and years of service for the firefighters and the two general populations are presented at the top of Table 4. For firefighters, age and years of service were highly correlated $(y=0.93, P<0.001)$.

Table 4 shows a comparison of firefighters' median and 90th percentile HTLs $(n=912)$ with those of KONP $(n=1130)$ and KNINEP $(n=1231)$ by age and frequency. The table consists of 60 cells comparing the HTLs of the three groups. The cells with italic letters indicate that the KONP threshold was worse than that of the firefighters. The cells with bold letters indicate that the KNINEP population was worse than the firefighters at that age and frequency. The HTLs of firefighters were worse than those of the KONP group in $88.3 \%(53 / 60)$ of the 60 comparisons and worse

Table 2. Results of the generalized linear model (log link, Poisson distribution) for hearing loss in firefighters $(N=912)$ with the KNOP $(N=677)$ as a reference.

\begin{tabular}{|c|c|c|c|c|c|}
\hline & $P R$ & $\mathrm{Cl}$ & $\beta$ & $S E$ & $P$ \\
\hline \multicolumn{6}{|c|}{ Service duration (month) as a main role } \\
\hline Rescuer & 1.010 & $1.007 \sim 1.013$ & 0.0101 & 0.0015 & $<0.0001$ \\
\hline Paramedic & 1.006 & $1.003 \sim 1.012$ & 0.0064 & 0.0019 & 0.0008 \\
\hline Driver & 1.004 & $1.002 \sim 1.006$ & 0.0046 & 0.0010 & $<0.0001$ \\
\hline Suppressor & 1.004 & $1.002 \sim 1.006$ & 0.0039 & 0.0011 & 0.0001 \\
\hline Office worker & 1.004 & $1.001 \sim 1.006$ & 0.0038 & 0.0014 & 0.0012 \\
\hline Ref. $^{a}(N=677)$ & 1.000 & & & & \\
\hline Age (years) & 1.022 & $0.9989 \sim 1.051$ & 0.0217 & 0.0115 & 0.0625 \\
\hline
\end{tabular}

than those of the KNINEP group in $66.7 \%$ (40/60) of the comparisons. Compared with the HTLs of KONP, firefighters' HTLs were significantly higher at most test frequencies with the exception at low frequencies $(0.5 \mathrm{kHz}, 1 \mathrm{kHz})$. In these frequencies, the HTLs of KONP was higher than Firefighters' HTLs among the age group over 31 years old, especially in age group of 51-60 years old. Firefighters' HTLs were worse than those of KNINEP in the younger age groups (24-30, 31-40, 41-45 years), but they were not different in the older age groups (45-50, 51-59 years). Younger age groups of firefighters had much worse HTLs than general populations at the 90th percentile, but the differences at the 50th percentiles (P50) between two populations decreased substantially.

\section{DISCUSSION}

The results of the age-adjusted analysis of hearing loss prevalence among male firefighters and general male populations showed that the prevalence of hearing loss was higher among firefighters than in an otologically screened general population (KONP) and similar to that of an unscreened general population (KNINEP). When considering the tasks, rescuers' HTLs were significantly worse than those of the two (screened and unscreened) general populations. To clarify the comparison, the data in Table 4 were illustrated using a median audiogram (Figure 1a-e). Figure 1 shows the median and 95\% confidence intervals for the firefighters' HTLs, stratified by age and audiometric test frequency, compared with the median thresholds of KONP and KNINEP. At this figure, there is one more line $(K O N P+2 \mathrm{~dB} \mathrm{HL})$ which, not depicted in the Table 4, is added $2 \mathrm{~dB} \mathrm{HL}$ to all raw data of KONP. This line was for reconciling and comparing the data by different step sizing in audiometric test (2-dB step sizing in the KONP versus $5-d B$ step sizing in the firefighters). HTLs collected with a 2-dB step size protocol is maximum $2 \mathrm{~dB}$ lower (better) than 5 - $\mathrm{dB}$ step size protocol in audiometric test. ${ }^{16}$ Assuming that all thresholds of KONP were measured by using 5-dB step size protocol and were $2 \mathrm{~dB}$ higher than those measured by using 2-dB step size, KONP's prevalence of hearing loss would be still significantly lower than that of firefighters $(P R=1.85, P<0.001)$. Though considering $2-d B$ adjustment to the 2-dB step size protocol of KONP's HTLs, the proportion of cells which showed higher Firefighters' HTLs than those of KONP (88.3\% in Table 4) was still $>50 \%$ (66.7\%).

In this study, firefighters' hearing level was compared with data obtained from a general representative Korean population instead of simply comparing their acuity with data from International Standards Organization (ISO1999) or ANSI S3.44. ${ }^{17,18}$ To our knowledge, this is the first reported study in Asia that assessed firefighters' hearing acuity comparing those of screened and unscreened general population.

Table 3. Results of the generalized linear model (log link, Poisson distribution) for hearing loss in firefighters $(N=912)$ with the KNINEP $(N=1231)$ as a reference.

\begin{tabular}{|c|c|c|c|c|c|}
\hline \multicolumn{6}{|c|}{ Service duration (month) as a main role: } \\
\hline Rescuer & 1.005 & $1.002 \sim 1.007$ & 0.0046 & 0.0013 & 0.0006 \\
\hline Driver & 0.999 & $0.997 \sim 1.000$ & -0.0014 & 0.0009 & 0.0893 \\
\hline Suppressor & 0.999 & $0.997 \sim 1.000$ & -0.0010 & 0.0010 & 0.2330 \\
\hline Office worker & 0.999 & $0.997 \sim 1.001$ & -0.0009 & 0.0011 & 0.4269 \\
\hline Ref. $^{a}(N=1231)$ & 1.000 & & & & \\
\hline
\end{tabular}




\begin{tabular}{|c|c|c|c|c|c|c|c|c|c|c|c|c|c|c|c|}
\hline Number & 54 & 226 & 160 & 262 & 348 & 374 & 213 & 160 & 162 & 187 & 153 & 170 & 197 & 243 & 365 \\
\hline Age $($ mean $\pm S D)$ & $29 \pm 2$ & $27 \pm 2$ & $27 \pm 2$ & $36 \pm 3$ & $36 \pm 3$ & $36 \pm 3$ & $43 \pm 1$ & $43 \pm 1$ & $43 \pm 1$ & $48 \pm 2$ & $48 \pm 1$ & $48 \pm 1$ & $54 \pm 2$ & $55 \pm 3$ & $55 \pm 3$ \\
\hline Years of service as a FF & $3 \pm 2$ & - & - & $8 \pm 5$ & - & - & $16 \pm 3$ & - & - & $21 \pm 3$ & - & - & $26 \pm 4$ & - & - \\
\hline P50 & 10 & 9 & 7.5 & 7.5 & $11^{\mathrm{a}}$ & $10^{\mathrm{b}}$ & 10 & 10.5 & 10 & 10 & 13 & 10 & 10 & 15 & 12.5 \\
\hline P90 & 20 & 16 & 15 & 17.5 & 18 & 20 & 17.5 & 20.5 & 20 & 20 & 22 & 22.5 & 20 & 23 & 27.5 \\
\hline \multicolumn{16}{|l|}{ Frequency $1000 \mathrm{~Hz}$} \\
\hline P50 & 7.5 & 6.5 & 2.5 & 7.5 & 8 & 5 & 10 & 9 & 7.5 & 10 & 11 & 7.5 & 10 & 13 & 10 \\
\hline P90 & 20 & 13 & 10 & 20 & 13 & 15 & 20 & 15 & 17.5 & 20 & 18 & 17.5 & 20 & 20 & 27.5 \\
\hline P50 & 7.5 & 5 & 2.5 & 7.5 & 5 & 7.5 & 15 & 9 & 12.5 & 15 & 11 & 13.8 & 15 & 17 & 22.5 \\
\hline P90 & 25 & 14 & 11.3 & 32.5 & 14 & 22.5 & 37.5 & 18 & 45 & 35 & 23 & 40 & 42.5 & 29 & 52.5 \\
\hline \multicolumn{16}{|l|}{ Frequency $4000 \mathrm{~Hz}$} \\
\hline P50 & 10 & 6 & 5 & 12.5 & 7 & 12.5 & 20 & 12 & 20 & 20 & 16 & 22.5 & 22.5 & 22 & 32.5 \\
\hline P90 & 37.5 & 16 & 17.5 & 47.5 & 17 & 37.5 & 62.5 & 22 & 57.5 & 52.5 & 29 & 56.3 & 55 & 36 & 65 \\
\hline \multicolumn{16}{|l|}{ Frequency $6000 \mathrm{~Hz}$} \\
\hline P50 & 17.5 & 9 & 12.5 & 20 & 10 & 17.5 & 30 & 14 & 22.5 & 27.5 & 19 & 32.5 & 30 & 25 & 40 \\
\hline P90 & 40 & 18 & 26.3 & 57.5 & 20 & 42.5 & 65 & 28 & 65 & 62.5 & 33 & 62.5 & 65 & 40 & 72.5 \\
\hline
\end{tabular}

Hearing problems in firefighters have been a subject of interest mainly in the United Kingdom and North America. Previous related studies can be classified into two major types according to design: (1) cross-sectional studies and (2) longitudinal studies in a cohort of firefighters. First, cross-sectional studies are more common than longitudinal ones and can provide prevalences, prevalence rate ratios, and prevalence odds ratios of hearing loss in firefighters. The prevalence and PR in this study were consistent with firefighters' known risks for audiometric abnormalities, which were more pronounced than in previous studies. Hong et al. ${ }^{19}$ recently reported that $40.7 \%$ of 425 American firefighters had hearing loss, defined as PTA46 of $\geq 25 \mathrm{~dB}$ in the worse ear. Using the same index (worse ear PTA46 $\geq 25 \mathrm{~dB}$ ), the prevalence in this study was $54.5 \%$. Kales et al. ${ }^{8}$ reported high-frequency hearing loss (average of two ears PTA345 $\geq 25 \mathrm{~dB}$ ) and broad-frequency hearing loss (average of two ears PTA5124 $\geq 25 \mathrm{~dB}$ ) of $14.4 \%$ and $11.7 \%$, respectively. Applying the same definitions used in the study by Kales et al., ${ }^{8}$ the present study found hearing loss of $28.2 \%$ at PTA345 and $21.5 \%$ at PTA5124, much higher rates than those reported by Kales et al. ${ }^{8}$ The results for PRs for firefighters versus a screened general population from the ISO1999 Annex $A^{17}$ in Kales et al. ${ }^{8}$ were 2.9 for high-frequency hearing loss and 2.9 for broad-frequency hearing loss. Our study, using their definitions, yielded values of 4.5 and 2.6, respectively. Firefighters in Korea work in relatively poorer condition than US firefighters. Korean firefighters' weekly average working time is longer than that of US firefighters, by approximately $30 \mathrm{~h}$ (70 h in Korea versus $40 \mathrm{~h}$ in US), but little is being done to protect them, including HCPs. There are about 38,000 career firefighters in Korea. In 2011, their fatality rate was over three times than that in the United States (2.2 in
10,000 in Korea versus 0.61 in 10,000 in the US), which is a consistent pattern since $2003 .^{20,21}$

Some critics of comparative studies with screened populations (ISO1999 Annex A) have argued that the effects of occupational noise exposure may be overestimated, because highly screened populations generally include more people of relatively higher socioeconomic status (SES) and fewer people having possible risk factors of hearing loss, such as cigarette smoking and diabetes. $^{10,15,22,23}$ However, it seems that overestimation related to smoking or SES was small in this study. The social status of firefighters in Korea has been rising gradually. According to the latest survey, ${ }^{24}$ firefighters had a college graduation rate of $62.7 \%$, significantly higher than that of KONP (39.8\%). The smoking rate among firefighters was also much lower than that among KONP (37.6\% versus $58.8 \%$ ). Additionally, about $80 \%$ of the KONP subjects lived in the capital city (Seoul), where environmental noise, such as traffic noise, is high. This may account for the difference between KONP and the data in ISO1999 Annex A. The median HTLs for the 30-year-old age group at high frequencies ( $3 \mathrm{kHz}, 4 \mathrm{kHz}$, and $6 \mathrm{kHz}$ ) were $5 \mathrm{~dB}, 7 \mathrm{~dB}$, and $10 \mathrm{~dB}$ in KONP and 2, 2 , and $3 \mathrm{~dB}$ in ISO1999 Annex $A$, respectively; the values for those in their 50 s were $17 \mathrm{~dB}, 22 \mathrm{~dB}$, and $25 \mathrm{~dB}$ in KONP and $12 \mathrm{~dB}$, $16 \mathrm{~dB}$, and $18 \mathrm{~dB}$ in ISO1999 Annex A, respectively. ${ }^{17}$

Clark and Bohl ${ }^{10}$ argued that it was inappropriate to attribute differences in hearing between firefighters and a screened general population to occupational noise exposure, because the firefighters were not screened. These authors conducted a crosssectional study comparing Fort Worth, TX firefighters with unscreened general population from the International Standard Organization (ISO1999 Annex B). ${ }^{17}$ They constructed a table showing $72 \mathrm{HTL}$ comparisons between the two populations, 

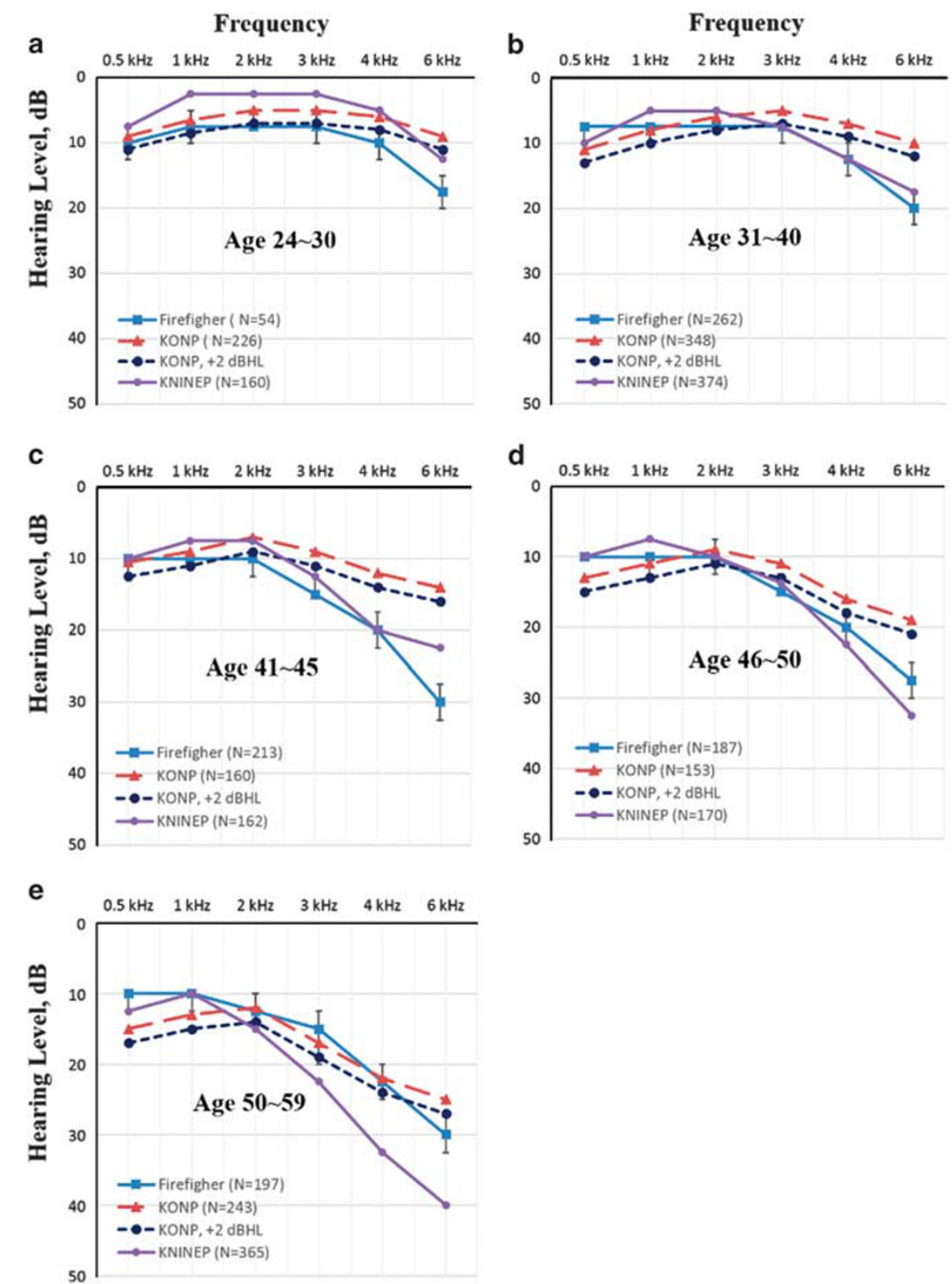

Figure 1. Median HTLs (dB HL) by age group for firefighters, KONP and KNINEP: (a-e) 24-30, 31-40, 41-45, 46-50 and 51-59 years, respectively. Firefighters shown as squares, KONP as triangles, KONP $(+2 \mathrm{~dB} H \mathrm{HL})$ as large circles and KNINEP as small circles. KONP $(+2 \mathrm{~dB} H \mathrm{HL})$ was a $2-\mathrm{dB}$ adjustment to the 2-dB step size protocol of KONP's HTLs to compare with the 5-step size protocol of firefighters' HTLs. The 95th percentile upper and lower confidence intervals of firefighters' median HTLs are represented by the vertical bars.

representing three percentile levels, six frequencies, and four age groups. In $43.1 \%$ of all comparisons, firefighters' HTLs were worse than those of the ISO1999 Annex B, which is not much lower than the $66.7 \%$ of comparisons between firefighters and KNINEP found in this study. Indeed, the differences were primarily at younger ages (younger than 45 years), although it was common that firefighters' hearing levels were better than those of the screened population at high frequencies $(3 \mathrm{kHz}, 4 \mathrm{kHz}$, and $6 \mathrm{kHz})$ in older age groups (older than 45 years).

Younger firefighters' hearing levels were obviously worse than those of members of the control groups in this study. There are a number of possible explanations for this. First, some occupational noise exposed individuals were likely not excluded from KNINEP. Occupational groups that might have experienced high noise exposure, such as agricultural workers, forestry and fishery workers (6.8\%), plant and machine operators (19.3\%), and routine and repetitive physical workers (5.7\%), were included; by an ageadjusted Cochran-Mantel-Haenszel test, their prevalence was significantly higher than that of the other types of workers in KNHANES 2011 ( $P R=1.09, \mathrm{Cl}: 1.01-1.18)$. Our criterion specifying "loud noise emitted from machine or generator for at least 3 months" may have been too narrow to screen for occupational noise exposure. Second, the response rate for KNINEP was relatively low, so the prevalence in KNINEP may not be truly representative of the unscreened general population. The KNHANES 2011 included audiometric examinations on the full sample of subjects aged 12-97 years, with a response rate of $59.5 \%$ (6302 people tested), which might have resulted in oversampling of relatively unhealthy, low-income persons. The proportion of low-income subjects included in KNINEP was $45.5 \%$, whereas most firefighters have mid-level incomes. The higher current smoking rate of KNINEP subjects compared with 
firefighters in general (42.9\% versus $38 \%$ ) might also have been a source of bias, as smoking has been reported to be significantly associated with an increased risk of high-frequency hearing loss. ${ }^{23}$ Third, there may be some problems with the audiometric tests in KNHANES. The audiometric data in KNHANES 2011 were the third since the audiometer and audio booth were changed in 2009. Hearing threshold data prior to the 2009 survey are not available. However, audiometric testing had been conducted in mobile examination centres, that is, two trailers linked together for use at each health examination site. The guidelines for the survey had no information about ambient noise levels in the room or any detailed guidance to avoid temporary threshold shifts. Fourth, there may be unique characteristics of Korean firefighters, such as occupational mobility, with or without job mobility (promotion within fire departments). About $20 \%$ of firefighters quit their job within 5 years after appointment, ${ }^{25}$ and $1.4 \%$ of firefighters retire early every year. ${ }^{26}$ There were no studies in Korea whether their mobility is associated with their infirmities, including hearing loss and so on. Firefighters are usually promoted to supervisory roles when they reach their 50s. Supervisory firefighters usually work only in the daytime, instead of alternating 24-h shifts, so their period of occupational noise exposure decreases. It has been reported that firefighters with supervisory roles had significantly lower noise exposure than did those in non-supervisory roles, who were almost always younger firefighters. ${ }^{27}$ Fifth, a learning effect, that is, an artificial improvement in hearing level, is one possible reason for these findings, as firefighters are expected to have a medical examination once a year, including an audiometric test. Although this audiometric test is not used for any HCPs, it is a requirement. Finally, there may have been some increase in noise exposure levels over time. The number of dispatches has increased fivefold over the past decade, whereas the number of firefighters has increased only 1.5 fold over the same period. ${ }^{20}$

Thus, several possible explanations as to why hearing acuity was worse in the younger firefighters than in the age matched general population (KNINEP) can be suggested. However, given that firefighters must also pass a rigorous physical examination to qualify for duty, including hearing loss of $<40 \mathrm{~dB}$, the findings are not readily explained. In a cross-sectional study, it is difficult to avoid confounding bias (disparity in health status between the groups) and selection bias (e.g., healthy worker effects), which are also limitations of this study. The only way to control for such bias would be to establish a baseline HTL and risk factor distributions for the firefighters and for the general population. ${ }^{28,29}$

To our knowledge, three longitudinal studies have evaluated firefighters' hearing over time. Tubbs showed that Hamilton, $\mathrm{OH}$ firefighters' mean hearing level at $4 \mathrm{kHz}$ declined by $3 \mathrm{~dB}$ (from $21 \mathrm{~dB}$ HL to $24 \mathrm{~dB} \mathrm{HL}$ ) over 6 years. ${ }^{30}$ Clark and Bohl reported that, despite deterioration by $4.2 \mathrm{~dB}$ at the same frequency over 7 years, the hearing of Phoenix, AZ firefighters did not decline, considering the role of presbycusis Appendix F1 of OSHA standard 1910.95. Their results are consistent with our findings for firefighters in their mid-40s and $-50 \mathrm{~s} .{ }^{10,31}$ Figure 2 is from the study by Clark and Bohl's, and our data have been added to the figure. Data from Clark and Bohl are longitudinal and those from our study and from Kales et al. ${ }^{8}$ are cross-sectional. Positive values in longitudinal study indicate the progression of hearing loss during the measurement interval exceeded that expected due to age alone (presbycusis correction value of OSHA 1910.95). In cross-sectional studies, the positive value indicate that firefighters' hearing thresholds is worse than those of the same age groups from unscreened population. The results for firefighters $>45$ years of age are similar in the study by Clark and Bohl. However, in contrast to both of those studies, the average HTLs of the younger age groups (24-30, 31-40, 41-45 years) in the current study were worse than expected considering those of the control group (KNINEP). In recent years, related longitudinal research has been conducted in the early stages of firefighters' careers in the United

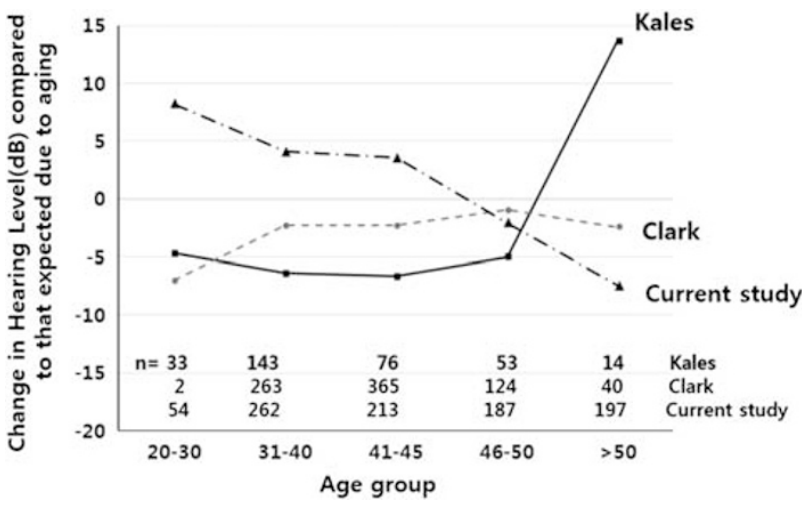

Figure 2. The differences between the firefighters' hearing thresholds (averaging the median thresholds at 3,4 and $6 \mathrm{kHz}$ ) and those predicted for persons of the same age groups from unscreened population from Kales' and current study. Dashed lines were from Clark and Bohl's longitudinal data, which was obtained by subtracting presbycusis correction value (Table F-1) of OSHA 1910.95 to interval between firefighter's first annual test and seventh annual test. This figure is cited from reference 11 (Clark and Bohl $\left.^{10}\right)$, and data from current study are added on that.

Kingdom. Ide ${ }^{9}$ reported that the hearing acuity of firefighters over a short period (mean 4.1 years) was reduced by about $30 \mathrm{~dB}$ (from $24.7 \mathrm{~dB}$ to $54.1 \mathrm{~dB}$ ) as the mean of left ear values averaged over $1 \mathrm{kHz}, 2 \mathrm{kHz}, 3 \mathrm{kHz}, 4 \mathrm{kHz}$, and $6 \mathrm{kHz}$, which is $>6 \mathrm{~dB}$ deterioration, on average, at each frequency. Those results are in good agreement with our study, which showed that the grand average HTL for firefighters in their 20s (mean 3 years of career) was higher than the unscreened general population by $33.6 \mathrm{~dB}(66.3 \mathrm{~dB}$ versus $32.7 \mathrm{~dB} ; P<0.001)$. Ide ${ }^{9}$ suggested that much of the reduction in hearing acuity in the early stages of firefighters' careers is due to the substantial amount of time spent in training with high noise exposure. An earlier cross-sectional study conducted by Reischl et al. ${ }^{6}$ also estimated that major hearing-level deterioration could occur during the first 3 years of fire service. Ide $e^{9}$ suggested that the evolution of firefighting techniques and accompanying increase in rescue training may be a cause of increased noise exposure, which is supported to some extent by our noiseexposure assessment. ${ }^{9}$

The higher prevalence among rescuers than among general population is consistent with results of recent noise-exposure studies in Korea. In our separate study on noise assessment (not published), rescuers were exposed to the highest mean level of noise (Lep, $d=84.6 \mathrm{dBA})$, followed by the driver $(83.3 \mathrm{dBA})$ and suppressor $(79.5 \mathrm{dBA})(P=0.04)$. Ahn et al. ${ }^{24}$ reported that noise level in and out of rescue truck cab (Leq24h $=72.1 \mathrm{dBA}$ in cab, $\operatorname{Lmax}=102.1 \mathrm{dBA}$ out of cab) was the highest than any other vehicles in fire department.

Briefly, this cross-sectional study showed some association between firefighters' experiences and hearing loss. However, causality cannot be established due to the cross-sectional nature of the study. To establish a causal connection between occupational noise and hearing loss among firefighters, a well-designed longitudinal study considering the other risk factors mentioned above is needed.

There are some other limitations beyond those described above; potential misclassification of exposure by simple screening question used to identify the KNINEP, possible underestimation of KNINEP's HTLs by audiometric testing in a mobile audiometric booth without noting a background noise, and so on. Military service information was not included in this study, which may also be a cause of hearing loss prior to current occupation. As South Korea has compulsory military conscription for all males, this effect may be 
smaller than in other countries with volunteer military system. However, as there is a substantial difference in noise exposure by military specialty, that not accounting for these potential exposures may introduce some uncertainty into this study.

\section{CONCLUSIONS}

The hearing thresholds of younger firefighters and rescuers were worse than expected by normal aging alone, although those of older firefighters did not differ from non-industrial noise-exposed controls. NIHL is irreversible and hearing acuity is one of the most important sense to firefighters' safety. Therefore, to prevent firefighters from hearing loss, HCP is required. Future research should include longitudinal studies to consider variable risk factors, such as military service, smoking, diabetes, and so on.

\section{CONFLICT OF INTEREST}

The authors declare no conflict of interest.

\section{ACKNOWLEDGEMENTS}

This research was supported by the Basic Science Research Program through the National Research Foundation of Korea (NRF) funded by the Ministry of Education, Science and Technology (No. 2011-0002926) and BK21 Plus project (22A20130012682). We appreciate the assistance of the Fire Science Research Center, Seoul Metropolitan Fire Service Academy.

\section{REFERENCES}

1 National Fire Protection Association. NFPA 1582, Standard on Comprehensive Occupational Medical Program for Fire Departments. National Fire Protection Association: Quincy, MA, USA, 2006.

2 Tufts JB, Vasil KA, Briggs S. Auditory fitness for duty: a review. J Am Acad Audiol 2009; 20: 539-557.

3 Kling RN, Demers PA, Alamgir H, Davies HW. Noise exposure and serious injury to active sawmill workers in British Columbia. Occup Environ Med 2012; 69: 211-216.

4 Moll van Charante AW, Mulder PG Perceptual acuity and the risk of industrial accidents. Am J Epidemiol 1990; 131: 652-663.

5 Hong O, Samo D, Hulea R, Eakin B. Perception and attitudes of firefighters on noise exposure and hearing loss. J Occup Environ Hyg 2008; 5: 210.

6 Reischl U, Bair HS, Reischl P. Fire fighter noise exposure. Am Ind Hyg Assoc J 1979; 40: 482-489.

7 Reischl U, Thrift GH, Reischl P. Occupation related fire fighter hearing loss. Am Ind Hyg Assoc J 1981; 42: 656-662.

8 Kales SN, Freyman RL, Hill JM, Polyhronopoulos GN, Aldrich JM, Christiani DC Firefighters' hearing: a comparison with population databases from the International Standards Organization. J Occup Environ Med 2001; 43: 650-656.

9 Ide CW. Hearing losses in wholetime firefighters occurring early in their careers. Occup Med (Lond) 2011; 61: 509-511 eng.

10 Clark WW, Bohl CD. Hearing levels of firefighters: risk of occupational noiseinduced hearing loss assessed by cross-sectional and longitudinal data. Ear Hear 2005; 26: 327

11 Lee JH, Kim JS, Oh SY, Kim KS, Cho SJ. Effects of age on hearing thresholds for normal adults. Kor J Audiol 2003; 7: 15-23.

12 American National Standards Institute, Acoustical Society of America, American Institute of Physics, Accredited Standards Committee on Bioacoustics -S3Maximum Permissible Ambient Noise Levels for Audiometric Test Rooms: ANSI S3.1-1991 (ASA 99-1991) [revision of S3.1-1977 (R 1986)]. Acoustical Society of America, 1996
13 Korea Centers for Disease Control and Prevention. Guide to the Utilization of the Data from the Fourth Korea National Health and Nutrition Examination Survey. Seoul, Korea, 2012.

14 National Institute for Occupational Safety and Health. Occupational Noise Exposure: Revised Criteria 1998. U.S. Dept of Health and Human Services, DHHS (NIOSH): Cincinati,OH, USA, 1998.

15 Dobie RA. Methodological issues when comparing hearing thresholds of a group with population standards: the case of the Ferry engineers. Ear Hear 2006; 27: 526-537.

16 Marshall L, Hanna TE, Wilson RH. Effect of step size on clinical and adaptive 2IFC procedures in quiet and in a noise background. J Speech Hear Res 1996; 39: 687-696.

17 International Organization for Standardization. Acoustics: Determination of Occupational Noise Exposure and Estimation of Noise-induced Hearing Impairment ISO 19992nd edn.ISO: Geneva, Switzerland, 1990.

18 American National Standards Institute. American National Standard Determination of Occupational Noise Exposure and Estimation of Noise-Induced Hearing Impairment - ANSI S3.44. ANSI: Washington, DC, USA, 1996.

19 Hong O, Samo DG Hearing loss and use of hearing protection among career firefighters in the United States. J Occup Environ Med 2013; 55: 960-965.

20 The National Emergency Management Agency. The Main Statistics of Korea NEMA. In: The National Emergency Management Agency, editor. 2012.

21 Fahy RF, LeBlanc PR, Molis JL. Firefighter Fatalities in the United States -2011. National Fire Protection Association: Quincy, MA, USA, 2012.

22 Hong O, Kerr MJ, Poling GL, Dhar S. Understanding and preventing noise-induced hearing loss. Dis Mon 2013; 59: 110-118.

23 Nakanishi N, Okamoto M, Nakamura K, Suzuki K, Tatara K. Cigarette smoking and risk for hearing impairment: a longitudinal study in Japanese male office workers. J Occup Environ Med 2000; 42: 1045-1049.

24 Ahn YS, Hyun SH, Jung KS, Kim KS, Choi KS, Choi JH. The Analysis of Risk factors related Health and Safety at Disasters and Development of special Medical Health Examination System for Firefighters. National Emergency Management Agency: Seoul, Korea, 2011.

25 National Emergency Management Agency. National Assembly's Annual Audit of National Emergency Management AgencyAgency NEM. editor. National Emergency Management Agency: Seoul, Korea, 2008.

$26 \mathrm{Na} \mathrm{Y-H}$. The deployment of fire facility and equipment inspection personnel in small fire station. J Kor Nat Fire Ser Aca 2004; 14: 1-30.

27 Kirkham TL, Koehoorn MW, Davies H, Demers PA. Characterization of noise and carbon monoxide exposures among professional firefighters in British Columbia. Ann Occup Hyg 2011; 55: 764-774.

$28 \mathrm{Li} \mathrm{C}-\mathrm{Y}$, Sung F-C. A review of the healthy worker effect in occupational epidemiology. Occup Med (Lond) 1999; 49: 225-229.

29 Siebert U, Rothenbacher D, Daniel U, Brenner H. Demonstration of the healthy worker survivor effect in a cohort of workers in the construction industry. Occup Environ Med 2001; 58: 774-779.

30 Tubbs R. Evaluating Risk of Noise Induced Hearing Loss for Fire Fighters (Publication No. 89-0026-2495). National Institute for Occupational Safety and Health Cincinnati, Ohio, USA, 1995

31 Occupational Safety and Health Administration. US Occupational Safety and Health Standards - CFR 1910.95. US Department of Labor (OSHA): Washington, DC, USA, 1983.

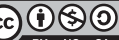

This work is licensed under a Creative Commons AttributionNonCommercial-ShareAlike 4.0 International License. The images or other third party material in this article are included in the article's Creative Commons license, unless indicated otherwise in the credit line; if the material is not included under the Creative Commons license, users will need to obtain permission from the license holder to reproduce the material. To view a copy of this license, visit http:// creativecommons.org/licenses/by-nc-sa/4.0/ 